\title{
Exemestane as primary treatment of oestrogen receptor-positive breast cancer in postmenopausal women: a phase II trial
}

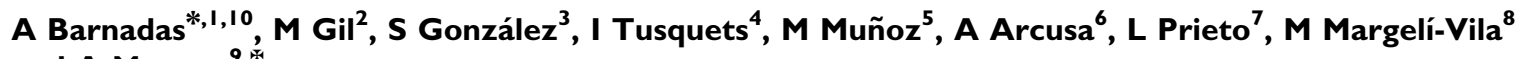 \\ and A Moreno",
}

'Medical Oncology Department, Hospital Universitari Germans Trias i Pujol, Institut Català d'Oncología, Badalona, Spain; ${ }^{2}$ Medical Oncology Department, Hospital Duran i Reynals, Institut Català d'Oncología IDIBELL, L'Hospitalet de Llobregat, Spain; ${ }^{3}$ Medical Oncology Department, Hospital Mútua de Terrassa, Terrassa, Spain; ${ }^{4}$ Medical Oncology Department, Hospital del Mar, Barcelona, Spain; ${ }^{5}$ Medical Oncology Department, Hospital Clinic, Barcelona, Spain; ${ }^{6}$ Medical Oncology Department, Consorcio Sanitario de Terrassa, Terrassa, Spain; ${ }^{7}$ Radiodiagnosis Department Hospital Universitari de Bellvitge, L'Hospitalet de Llobregat, Spain; ${ }^{8}$ Medical Oncology Department, Hospital Universitari Germans Trias i Pujol Institut Català d'Oncologia, Badalona, Spain; ${ }^{9}$ Pathological Anatomy Department, Hospital Universiari de Bellvitge L'Hospitalet de Llobregat, Spain

To assess the efficacy of exemestane as neoadjuvant treatment, 55 postmenopausal women (mean age: 76 years; range: 66-86) with oestrogen-positive non-metastatic breast tumour and ineligible for conservative surgery were recruited into this phase II trial to receive oral exemestane $\left(25 \mathrm{mg} \mathrm{day}^{-1}\right)$ for 6 months. Tumour response was evaluated by clinical examination, mammography and breast ultrasound every 2 months (RECIST criteria). Overall clinical response to treatment was observed in 33/54 patients (61.1\%; 95\% Cl: 48.1 -74.0). Radiological responses in 45 evaluable patients were partial response in 23, stable disease in 21 and disease progression in one. Median time to surgery from the commencement of treatment was 7 months; conservative surgery in 24 patients (55.8\%) and mastectomy in 19 patients (34.5\%); no surgery (patient choice or considered not suitable by attending physician) in 12 patients. Pathologic complete response was observed in breast and axilla in one patient (2.3\%) and different forms of persistent disease in 23 (53.5\%) patients. Treatment tolerance was good. No patient withdrew from the study because of toxic events. We conclude that exemestane as a primary treatment is feasible and very active in elderly patients with large-sized breast cancer tumour. Conservative surgery is feasible in responding patients. No severe adverse events were detected. The optimal hormonal treatment schedule remains to be determined.

British Journal of Cancer (2009) 1 00, 442-449. doi: I0. I038/sj.bjc.6604868 www.bjcancer.com

Published online 20 January 2009

(c) 2009 Cancer Research UK

Keywords: aromatase inhibitors; breast cancer; exemestane; neoadjuvant therapy; primary hormonal therapy

Breast cancer incidence increases with age; one-third of patients being $>65$ years of age when diagnosed (Landis et al, 1998). Further, the diagnosis of large volume tumours is most frequent in the elderly women. This observation is not because the tumour is biologically more aggressive at such an age but rather because, in many cases, these patients put off visiting their family practitioner or local medical centre and, as well, decline to participate in population screening programmes (Yancik et al, 1989).

The primary treatment for breast cancer has been to treat both operable and non-operable large size tumours, as well as to provide the patients with a conservative treatment option. Randomised trials have shown that this approach achieves this objective in a high proportion of cases, whereas diseasefree-survival (DFS) and overall survival (OS) are maintained

\footnotetext{
*Correspondence: Dr A Barnadas, Medical Oncology Department, Hospital de la Santa Creu i Sant Pau, Sant Antoni Maria Claret 167, Barcelona, 8025, Spain; E-mail: abarnadasm@santpau.cat

${ }^{10}$ Current address: Medical Oncology Department, Hospital Santa Creu i Sant Pau, Barcelona, Spain

Deceased

Received II September 2008; revised 19 November 2008; accepted 5 December 2008; published online 20 January 2009
}

(Bonadonna et al, 1990; Mauriac et al, 1990; Veronesi et al, 1995; Fisher et al, 1998; Moneer et al, 1999; Mauri et al, 2005).

Primary hormonal treatment is the appropriate option for treating postmenopausal women who have hormone-receptorpositive advanced tumours. The first trials were performed using tamoxifen as a single medical treatment, as opposed to surgery. A reduction in tumour size was noted in a remarkable proportion of patients (Gazet et al, 1994; Ellis et al, 2001).

Third-generation aromatase inhibitors rely on antitumour activity, superior to that of tamoxifen, in treating disseminated breast cancer in postmenopausal women. Similarly, letrozole appears to have a better activity profile than that of tamoxifen in the treatment of primary breast cancer (Eiermann et al, 2001; Ellis et al, 2001). In elderly women, primary hormonal treatment is considered the most appropriate option to avoid mutilation resulting from radical surgery. Tolerability of these drugs is acceptable, with only a small percentage of patients abandoning the therapy. The probability of achieving a better response is increased in relation to the level of oestrogen receptor (ER) expression (Ellis et al, 2001).

Exemestane, a steroid aromatase inhibitor, has a better antitumour activity than tamoxifen in the treatment of disseminated breast cancer, and with a low incidence of secondary adverse effects (Dixon et al, 2003; Paridaens et al, 2003). The initial results 
of a small scale phase II study suggested that exemestane, administered as primary treatment for locally advanced breast tumour, is capable of reducing tumour size in around $84 \%$ of patients (Miller and Dixon, 2002). A randomised phase II trial comparing primary chemotherapy with primary endocrine treatment has recently published (Semiglazov et al, 2007). The results show a similar effect in overall objective response to the two treatments and to breast conservation surgery in postmenopausal women with positive hormone receptor. However, in this trial, the primary treatment was administered only for 3 months.

We present the results of a phase II study, which was performed with exemestane as primary hormonal treatment in postmenopausal patients with breast cancer, and with a receptor-positive tumour of $\geqslant 3 \mathrm{~cm}$. The primary objective was to evaluate (using physical examination and imaging techniques including echography and mammography) the effectiveness of exemestane as a primary treatment administered for 6 months. The secondary objectives were to assess the proportion of patients who could benefit from a conservative treatment, and to histologically evaluate remission rates, the tolerability profile and the time-toprogression of the disease. Various clinical factors and molecular markers were evaluated in relation to the response-to-treatment achieved.

\section{PATIENTS AND METHODS}

Between November 2000 and June 2003, there were 55 patients recruited from seven Spanish institutions. The study was approved by the Ethics Committees of each institution. Before the patients were recruited into the study, informed consent was obtained from each participant on the understanding that the data from the trial would be used in determining the factors predictive of response while maintaining anonymity of the individual participants. All the patients fulfilled the following eligibility criteria: histological confirmation of breast carcinoma; nuclear staining of oestrogen receptors in $\geqslant 50 \%$ of tumour cells assessed with immunohistochemistry (IHC) techniques; $\geqslant 65$ years of age; and measurable disease in at least one dimension of the tumour; and any of the following clinical conditions to be ineligible for breast conservative surgery according the criteria of the surgical team and tumour size $\geqslant 3 \mathrm{~cm}$ or tumour stage $\mathrm{T}_{4 \mathrm{a}}, \mathrm{T}_{4 \mathrm{~b}}, \mathrm{~N}_{1}$ or $\mathrm{N}_{2}$. Patients needed to have a Karnofsky index $\geqslant 70$; appropriate haematological, hepatic and renal function and a life expectancy of at least 6 months. The exclusion criteria included being male; previous treatment with tamoxifen or aromatase inhibitors; inflammatory carcinoma or ulceration on the mammary glands $>50 \%$ of the volume; previous malignancy (except basocellular carcinoma or cervical carcinoma in situ appropriately treated); and distant metastases. The administration of other antineoplasic therapies and hormonal replacement treatment (HRT) were not permitted within the trial protocol.

\section{Treatment scheme}

The patients received $25 \mathrm{mg}$ exemestane orally once daily (Aromasil, Pfizer Spain) for a period of 6 months, unless disease progression was observed. Surgical treatment was scheduled for when this treatment period was completed, and exemestane was administered until the day before surgery. Depending on radiological and clinical findings at the conclusion of the treatment with exemestane, patients in whom it was considered possible were offered conservative treatment. According to the protocol of each participating institution, the patients subsequently received supplementary radiotherapy always on the mammary gland when conservative treatment had been performed, or on the thoracic wall and extended to the lymph nodes in case of locally advanced disease, or when three or more lymph nodes were involved.
Following surgery, most patients on hormone therapy with no progression of the disease proceeded on to adjuvant systemic treatment with exemestane for a period of 5 years.

\section{Study assessments}

All patients had histological confirmation by means of core needle biopsy, and, from which tissue, progesterone and ER status was determined using IHC techniques. HER2 expression was evaluated using HercepTest ${ }^{\mathrm{TM}}$ (DAKO A/S, Glostrup, Denmark, http://www. dakousa.com/prod_downloadpackageinsert.pdf?objectid =114969002). The expression of $\mathrm{p} 53$ proteins as well as BCL-2 and BCL-X (using antibodies against p53, Ab2 and Ab-6, respectively) was assessed using IHC techniques. Apoptosis was measured using the TUNNEL technique $(>$ or $<1 \%$ ). All immunochemistry and histological determinations were reviewed by a single investigator of the team (AM) who was blinded with respect to the clinical course of the disease. Before the start of treatment, the patients underwent the following evaluations: physical examination, haemogramme and blood biochemistry constituents, including renal function and liver enzymes, bilateral mammography, chest X-ray, bone scan and abdominal echography. The diameter of every lesion was measured, and in case of suspected adenopathies determined on palpation, these were confirmed by cytology on tissue obtained by biopsy. Pathology examination was performed by a pathologist of each institution, who was provided with tumour assessment guidelines, following the criteria proposed by the Aberdeen group (Walker et al, 1999) before starting the trial. Patients without residual infiltrating cancer or DCIS in the breast and in the axilla were considered to have had a pathological complete remission, and status was reviewed by one investigator (AM). The follow-up evaluation comprising physical examination, mammography and/ or breast echography commenced at 1-month post-treatment and continued every 2 months thereafter. The RECIST methodology was used to assess response (Therasse et al, 2000). After surgery, the patients were followed-up every 6 months. Blood chemistries, chest X-rays and mammographies were performed annually. In case of disease progression during the primary hormone treatment stage, the patient was transferred out of the trial and subsequent treatment was left to the discretion of the individual investigator.

Tolerance to treatment was assessed according to the methodology described by the NIH (NIH, 1998).

\section{Statistical methods}

The design of the study was according to Simon's method in which the desired minimum activity was defined as $20 \%$ and the maximum was $40 \%$. Assuming an $\alpha$-error of 0.05 and a $\beta$-error of 0.1 , the minimum number of patients required was estimated as 19 and the maximum as 54. The two-stage model was chosen with the purpose of terminating the trial if a minimum of four objective responses was not obtained out of the 19 patients. If such an index corresponded to 15 out of the first 19 patients, the study would be terminated as well. If none of these possibilities occurred, the study would continue until 54 patients had been recruited.

The progression-free survival was calculated from the moment of the patient's inclusion until progression occurred. Response duration was calculated from the time of detection of response until disease progression. Overall survival was estimated from the time of the patient's inclusion into the trial until death from any cause. Values are expressed as odds ratio (OR) and $95 \%$ confidence interval $(95 \% \mathrm{CI})$. Significance level was set at $P<0.05$.

\section{RESULTS}

This study included a total of 55 women. Of these, 54 were evaluable for assessment of response and toxicity, and one patient 
Table I Characteristics of the patients $(n=55)$ on entry into the trial

\begin{tabular}{lc}
\hline Characteristic & $\boldsymbol{n}$ \\
\hline Patients evaluable for response & 54 \\
Mean age; years (range) & $77(66-87)$ \\
Primary tumour & 32 \\
T2-T3 & 23 \\
T4 & \\
Lymph node involvement & 30 \\
NO & 20 \\
NI & 5 \\
N2 & \\
Histology grade & 3 \\
Gl & 24 \\
GII & 6 \\
GIII & 22 \\
Not known & \\
ER status & \\
ER+:50-60\% & 12 \\
ER+:70-80\% & 13 \\
ER+:90-95\% & 29 \\
HER2 overexpression & \\
Karnofsky index & $(14.5 \%)$ \\
I00\% & 34 \\
$90 \%$ & 9 \\
$80 \%$ & 5 \\
$70 \%$ & 6 \\
\hline RR &
\end{tabular}

$E R=$ oestrogen receptor

Table 2 Response segregated with respect to end-of-treatment evaluation

\begin{tabular}{lcccc}
\hline Assessment & CR & PR & SD & PD \\
\hline Physical examination $(n=54)$ & $3(5.7 \%)$ & $30(57 \%)$ & $19(36 \%)$ & $2(2.3 \%)$ \\
Mammography $(n=46)^{\mathrm{a}}$ & 0 & $23(51 \%)$ & $21(47 \%)$ & $2(2 \%)$ \\
Mammary echography $(n=36)^{\mathrm{b}}$ & 0 & $18(52 \%)$ & $16(46 \%)$ & $2(2 \%)$ \\
\hline
\end{tabular}

$\mathrm{CR}=$ complete response; $\mathrm{PR}=$ partial response; $\mathrm{SD}=$ stable disease; $\mathrm{PD}=$ progressive disease. ${ }^{a}$ In eight patients, the end-of-treatment mammography had not been performed. ${ }^{b}$ In 18 patients, the end-of-treatment echography had not been performed.

withdrew her consent to further participation after the first $24 \mathrm{~h}$ of treatment. At the time of inclusion, all patients were ineligible for conservative surgery, according to the surgical team's criteria. Half of patients had locally advanced disease. The patients' characteristics are summarised in Table 1. Following 6 months of treatment, an objective clinical response was observed in 33 patients (global index: 61.1\%; 95\%CI: 48.1-74\%); complete clinical remission was achieved in three patients (5.5\%; 95\% CI: $0-11.5 \%)$ and partial remission in 30 patients (55.5\%; 95\% CI: 42.3-68.2\%). Stabilisation was observed in 19 patients that represents $35.1 \%$ of patients who began primary treatment with exemestane. Local disease progression without metastases was observed in two patients (3.7\%; 95\%CI: $0-8.7 \%)$; one after the 4 th month, and the other after the 6th month of the treatment. The first patient had HER2positive tumour, whereas in the other HER2 overexpression was not present. On progression, these patients had chemotherapy administered and subsequent surgery. The clinical benefit obtained was around $96.1 \%$.

Table 2 summarises the responses and the end-of-treatment assessments. All the patients underwent imaging evaluations (mammography and/or echography) every 2 months and at the

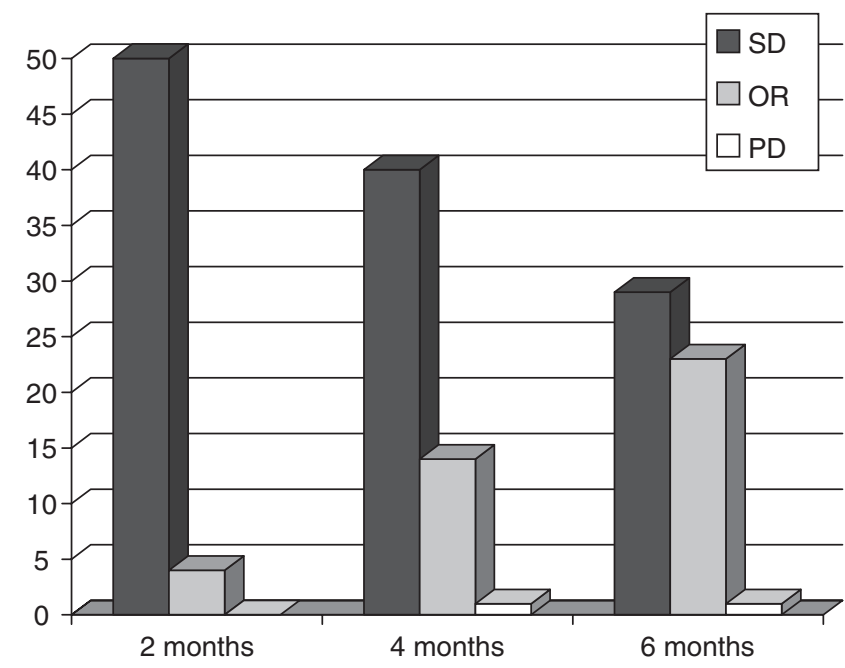

Figure I Response to treatment as evaluated by mammography. $\mathrm{SD}=$ stable disease; $\mathrm{OR}=$ objective response; $\mathrm{PD}=$ progressive disease

end of the treatment period. Figure 1 depicts the mammography response in relation to treatment period.

One of the secondary objectives of the study was to evaluate the type and effect of surgery after 6 months of treatment. There were 11 patients who were not operated upon; in eight cases the patients refused the surgical option despite having had a partial remission or stabilisation with a good tolerance to the medication; two cases with local disease progression had chemotherapy before the surgical intervention; one case was not referred for surgery because of medical contraindications to anaesthesia. Hence, 43 women underwent breast surgery; 24 patients $(55.8 \%)$ had a lumpectomy and 19 patients (44.2\%) had a mastectomy (in some cases such surgery was specifically requested by the patient). An axilla lymphadenectomy was performed in 36 of the 43 patients undergoing surgery (Table 3 ).

With respect to pathological remissions in one case $(2.3 \%$; $95 \%$ CI: $0-6.7 \%$ ), the remission was ganglionar and locally complete, the histological type was an infiltrating lobular carcinoma; in 23 cases $(53.5 \%$; 95\%CI: $33.1-73.8 \%)$, there were signs of inflammation, necrosis and fibrosis with presence of local small infiltrating ducal carcinoma nests; and in 19 cases $(44.1 \%)$, no evidence of local histological response was observed (Table 3 ).

Analysis of the factors predictive of response included age, tumour size, ER level, general clinical status and presence or absence of axilla lymph node involvement. Only the presence of ER $\geqslant 90 \%$ was statistically significantly associated with radiological response rate ( 73 vs 32\%; $P=0.0026$; OR: $5.7,95 \%$ CI: $1.7-18.5$ ). Age $(\leqslant 76 v s>76$ years), tumour size (T2 $-\mathrm{T} 3$ vs T4), Karnofsky index $(<100$ vs 100\%) and axilla involvement (N0 vs $\mathrm{N} 1-\mathrm{N} 2)$ showed no significant relationship with radiological response. HER2 overexpression was detected in eight cases (14.5\%), and TUNNEL $>1 \%$ was detected in $13 \%$ of the patients. HER2, BCL-2, BCL-x, BAX and p53 expression were not significantly related to the clinical response. The small number of patients precluded significant correlations between these variables being detected.

Tolerance to treatment was good during the presurgical treatment phase. However, two cases had transient cerebral vascular ischaemia during the adjuvant treatment. No other grade III or IV toxicity was detected. There were no withdrawals from the study due to the treatment. The main secondary effects are summarised in Table 4. Notably, all secondary effects were of low intensity and were quickly resolved.

Following surgery, the patients were followed up for an average of 48 months (range: 10-72) during which time 15 deaths 
Table 3 Characteristics and outcome of the surgery

Characteristics and outcome

n (\%)

Type of surgery: 43 cases underwent surgery following exemestane administration Conservative surgery Mastectomy

24 of $43(55.8)$

19 of $43(44.2)$

24 of $54(44.8)$

Pathologic response

Response

CR G5

PR G3+G4

Local

13

Response

CR D

CR D

PR C

No response $B$

Not performed

PR C

No response $B$

Not performed

19 of $54(35.2)$

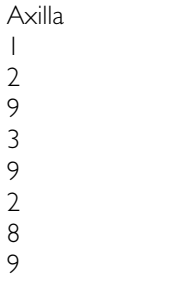

$\mathrm{CR}=$ complete response; PR = partial response. Pathologic response assessment according Miller and Payne classification (Walker et al, I999). G5: absence of residual infiltrating tumour cells. G4: marked disappearance of invasive tumour cells; only small clusters of widely dispersed cells could be detected. G3: considerable reduction in tumour cells. G2: mild loss of invasive tumour cells, but overall cellularity still high. Gl: no reduction in overall numbers as compared with pre-treatment biopsy. B: lymph node positive with malignant cells. C: lymph node still positive, but with evidence of some regression. D: lymph node without metastases, previously were positive. In a total of I 8 patients, axilla lymphadenectomy was not performed (decision of the surgical team or of the patient).

Table 4 Adverse effects according to $\mathrm{NCl}$ scale

\begin{tabular}{lcc}
\hline Event & N & $\%$ \\
\hline Hot flushes & 12 & 22 \\
Nausea/vomiting & 5 & 9 \\
Abdominal pain & 3 & 5.5 \\
Asthaenia & 5 & 9 \\
Musculoskeletal pain & $12^{\text {a }}$ & 22 \\
Dizziness & 4 & 7.4 \\
Skin rash & 3 & 5.5 \\
Peripheral oedema & 3 & 5.5 \\
Constipation & 2 & 3.7 \\
Pruritis & 3 & 5.5 \\
Alopaecia & 3 & 5.5 \\
Dry mouth & 3 & 5.5 \\
Anorexia & 4 & 7.4 \\
Headache & 4 & 7.4 \\
\hline
\end{tabular}

All the observed adverse effects corresponded to grades I and II, except one case of grade III arthralgia and one case with a grade IV episode of cerebral ischaemia. ${ }^{\text {a One }}$ of the cases was of grade III.

occurred. The deaths were reported as eight being due to the breast cancer and seven to other causes not related to neoplasic disease. Locoregional progression was observed in 13 patients $(23.6 \%)$ - in five patients who had undergone surgery and in eight who had not. Distant metastases were detected in eight cases. Among the five patients treated with surgery who had local disease progression or lymph node involvement, only one had been treated with conservative surgery and had disease progression in the supraclavicular lymph node region. None of these patients had had pathological response. Median time to progression-free survival, in $42.5 \%$ patients observed at this time, was not reached at 61 months (data not shown).

\section{DISCUSSION}

Surgical treatment plays an important role in the management of most cases of mammary neoplasms. When breast lesions are small in size, a treatment conserving the mammary gland is possible, with good cosmetic results, good acceptance by the woman and without an additional risk of recurrence or mortality (Gazet et al, 1994; Eiermann et al, 2001; EBCTCG 2005). When breast tumours are large sized, generally $>4 \mathrm{~cm}$, radical mastectomy is the recommended treatment. This has a higher morbidity risk and, above all, a greater negative impact on women who have the disease. In the case of elderly women, mastectomy is tantamount to mutilation and the emotional impact is as strong as in younger women. Patients $>70$ years of age also have a tendency to prefer breast-conserving surgery over mastectomy (Sandison et al, 1996). Some investigators have compared local relapse rates following conservative treatment in patients above and below the age of 65 years. Their reports indicate $4 \%$ relapse rate at 10 years in patients aged $>65$ years compared to $13 \%$ in those below this age (Merchant et al, 1995). Further, tolerance to radiotherapy is no worse in the elderly than in the younger patients. Therefore, age should not be an exclusion criterion for conservative surgery.

When offering conservative surgery to those patients whose tumour at diagnosis is of a size that implies inoperability, primary treatment before surgery needs to be administered. Randomised primary hormone therapy or chemotherapy studies have not been able to show a benefit regarding a reduction of mortality risk due to cancer. However, they have shown an increase in the number of patients in whom radical surgery on the breast can be avoided (Yancik et al, 1989; Mauriac et al, 1990; Bonadonna et al, 1990; Gazet et al, 1994; Veronesi et al, 1995; Fisher et al, 1998; USNCI, 1998; Moneer et al, 1999; Mauri et al, 2005).

In postmenopausal patients, primary hormonal treatment with tamoxifen has shown high effectiveness in achieving the previously defined goals. Tamoxifen has, over many years, achieved response rates ranging from 30 to $60 \%$ (Allan et al, 1985; Horobin et al, 1991; Bergman et al, 1995; Keen et al, 1997; Gil et al, 2001), and, as such, avoiding radical surgery in a high proportion of elderly patients. All the studies observed a very low progression rate, ranging between 5 and $8 \%$ (Smith, 1991), but, on extended follow-up, most patients had local progression and needed some radiotherapy or surgical treatment (Robertson et al, 1992; Kenny et al, 1998). Some studies have observed an average duration, $24-30$ months, of response to primary hormonal treatment (Smith, 1991).

In several randomised trials (Gazet et al, 1988; Kenny et al, 1998), the overall survival in patients $>70$ years of age was similar when the effectiveness of tamoxifen as a single treatment was compared with surgery. However, local control was better among the group of patients who had been operated upon. Two further randomised trials have been conducted comparing tamoxifen monotherapy and surgery followed by tamoxifen in patients $>70$ years of age. With an average follow-up period of 5 years, both studies concluded that the group treated with surgery presented less local progressions/relapses, although the overall survival of patients $>73$ years of age was approximately the same. Conservative surgery achieved the same results as mastectomy for local control (Bates et al, 1991; Mustacchi et al, 1994). Hence, 
surgery appears not to have a great influence on survival of those patients $>73$ years of age who have tumours with positive hormonal receptors.

Aromatase inhibitors have been shown to have greater activity than tamoxifen in the first-line treatment of disseminated breast cancer (Buzdar and Howell, 2001; Paridaens et al, 2003; Wong and Ellis, 2004). Similarly, a double-blind randomised study showed the superiority of primary treatment with letrozole $v s$ tamoxifen over 4 months in postmenopausal women. The overall response rate achieved with letrozole was 60 vs $41 \%$ with tamoxifen (Eiermann et al, 2001; Ellis et al, 2001). The double blind IMPACT study (Smith et al, 2005) compared the administration of anastrozole $v s$ tamoxifen over a period of 3 months. No differences were observed in the response rates ( $27 \%$ vs $36 \%$ ), although patients assigned to the anastrozole arm showed a greater response rate to conservative surgery (67 vs 56\%). The PROACT study (Cataliotti et al, 2004) also used a randomised double-blind methodology to compare anastrozole with tamoxifen administered over 3 months in locally advanced breast carcinoma. Significant differences in response rates were not observed (39 vs 35\%), but a greater proportion of patients treated with anastrozole benefited from conservative surgery. The preliminary results of a small randomised study (Semiglazov et al, 2005), which was not double blind and which compared exemestane with tamoxifen treatment over 3 months, showed an objective clinical remission rate of around $76 \%$ compared to $40 \%$ with tamoxifen. However, in another German phase II study (Astner et al, 2004) containing 29 patients in whom exemestane had been administered for 4 months, the clinical response rate was approximately $37 \%$.

In a randomised trial comparing four cycles of adriamycin and paclitaxel with anastrozole or exemestane administered over 3 months, a similar objective response was reported together with low breast-conserving surgery rates plus endocrine therapy (Semiglazov et al, 2007). Further, the clinical response rates were similar to that obtained in this study.

The probability of achieving a better response has been related to the level of hormonal receptors. In the study by Ellis et al (2001), higher response was observed when the Allred score was $>5$, or when percentage of ER-positive cells were $\geqslant 50 \%$ (Gil et al, 2001). To avoid including patients with a lower probability of response to hormonal treatment over 6 months, the ER expression cutoff $\geqslant 50 \%$ was introduced as an inclusion criteria.

Several groups have observed discordance in response rates, depending on the method used for response evaluation. For example, physical examination tends to be associated with an increase in the proportion of remissions observed, compared to mammary echography or mammography, the latter two assessments being more concordant (Eiermann et al, 2001; Ellis et al, 2001; Semiglazov et al, 2005). This study confirmed that response assessments performed radiologically were not concordant with physical examination. We believe that, among the subgroup of elderly patients, mammography is the most useful and reliable method except in those specific cases where tumour outlines cannot be defined accurately by baseline mammography. In such cases, echography would be the preferred method to assess the response to treatment (Table 5).

Although the optimum time period for hormonal treatment has not been extensively explored, some studies suggest that the maximum response is obtained during the first 3-4 months of treatment, whereas other investigators state that $>9$ months can elapse before a response is achieved (Allan et al, 1985; Gil et al, 2001; Krainick-Strobel et al, 2008). In this study, a preoperative treatment period of 6 months was proposed. This follows from earlier experience with toremifene in which patients were referred to surgery at the time of maximum response and in which followup was every 3 months; the median time necessary to document a response according to UICC criteria (Gil et al, 2002) was 6 months. Studies performed with primary chemotherapy over 6 months have shown greater pathologic complete remission rates compared to studies using 3-month designs. In this study, we performed a radiological assessment of the response on a bimonthly basis. We need to emphasise that of the 23 cases showing partial mammographic remission, only 4 had achieved this response within 2 months, as compared to 14 cases in whom the response occurred after 4 months and 23 cases in whom the response occurred after 6 months. The IMPACT and PROACT studies employed only 3 months of treatment before surgery. Both reported lower response rates relative to other studies in which aromatase inhibitors, as well as tamoxifen, had been administered. These data suggest that the minimum duration of the primary hormonal treatment should be 4 months, although a longer time period might be advisable. This hypothesis needs to be validated in a randomised clinical trial format.

One of objectives of the primary treatment was to offer a conservative treatment to patients in whom the initial volume of the disease would not normally permit this option. Aromatase inhibitors have provided an improvement in this respect, such that in randomised studies comparing these drugs with tamoxifen, $>48 \%$ of patients were able to benefit from the conservative treatment option. This percentage is greater than that observed with tamoxifen alone (Gazet et al, 1994; Ellis et al, 2001; Astner et al, 2004; Cataliotti et al, 2004; Smith et al, 2005; Semiglazov et al, $2005)$. In this study at the end of the treatment, $56 \%$ of the patients who accepted the surgical option were acceptable for conservative treatment. Of note is the clinical evolution of patients who chose not to undergo surgical treatment, that is, on many occasions elderly women who observe an improvement in their lesions are fearful of surgery. They choose not to undergo surgery even after being informed of the risk of disease progression, both at a locoregional level and in the form of metastases. On the other hand, some patients preferred to undergo a mastectomy to avoid later radiotherapy, even though they had responded to primary treatment.

There have been very few studies on the effectiveness of hormone therapy compared with chemotherapy. An earlier randomised study by the EORTC contained 410 patients with locally advanced breast carcinoma. The study scheme compared radiotherapy alone vs radiotherapy plus CMF chemotherapy, or radiotherapy plus tamoxifen or radiotherapy plus CMF plus tamoxifen (Bartelink et al, 1997). The group of patients receiving chemotherapy plus hormone therapy was the only group that achieved a significantly higher progression-free survival. When the chemotherapy arm was compared with the no-chemotherapy arm, no significant differences were observed. However, the comparison of patients receiving tamoxifen $v s$ no tamoxifen showed significant differences. More recently, data have been reported (Semiglazov et al, 2007) from a randomised study comparing primary chemotherapy with doxorubicin plus paclitaxel vs primary hormone therapy with anastrozole or exemestane. No significant differences were observed with respect to either the clinical or radiological response rates.

In primary chemotherapy, achieving a complete pathologic response is associated with a better prognosis (Yancik et al, 1989; Bonadonna et al, 1990; Mauriac et al, 1990; Veronesi et al, 1995; USNCI, 1998; Mauri et al, 2005), but whether this is the same for hormone therapy is not known. In the series of patients treated with primary hormone therapy, the percentage of patients having a pathologic complete remission was never $>5 \%$. Indeed, in the randomised study (Ellis et al, 2001; Eiermann et al, 2001) conducted with letrozole, the percentage of histological complete remission was $1 \%$, and in the randomised study using anastrozole (Smith et al, 2005), the pathologic complete remission rate had not been described. In the study performed by Astner et al (2004), no complete remission was observed. However, a reduction of the tumour size was noted in a large proportion of patients. In this study, the incidence of pathologic complete remission was 
Table 5 Responses and surgery type segregated according to the outcomes from primary hormone therapy

\begin{tabular}{|c|c|c|c|c|c|}
\hline Drug (References) & Patients $n$ & Clinical response & Mammography & Echography & Conservative surgery \\
\hline Tamoxifen (Eiermann et al, 200 I) & 126 & $\begin{array}{l}52(41 \%) \\
P<0.001\end{array}$ & $\begin{array}{c}25(20 \%) \\
<0.001\end{array}$ & $\begin{array}{l}37(29 \%) \\
P=0.042\end{array}$ & $\begin{array}{l}45(36 \%) \\
P=0.022\end{array}$ \\
\hline Anastrozole & 113 & $42(37 \%)$ & & $27(24 \%)$ & $21 / 46(46 \%)$ \\
\hline Anastrozole+Tamoxifen & 109 & $31(28 \%)$ & & & $11 / 42(26 \%)$ \\
\hline Tamoxifen (Smith et al, 2005) & 108 & $39(36 \%)$ & & $22(20 \%)$ & $8 / 36(22 \%)$ \\
\hline \multirow[t]{2}{*}{ Tamoxifen (Semiglazov et al, 2005) } & 37 & $19(5 \mid \%)$ & $15(40 \%)$ & $15(40 \%)$ & $4(11 \%)$ \\
\hline & & $P=\mathrm{n} / \mathrm{s}$ & $P=n / s$ & $P=0.088$ & $P<0.05$ \\
\hline Exemestane (Astner et al, 2004) & 29 & $10(35 \%)$ & & & $14(48 \%)$ \\
\hline Exemestane (current study) & 54 & $33(61 \%)$ & $23(51 \%)$ & $18(51.4 \%)$ & $21(56 \%)^{\mathrm{a}}$ \\
\hline
\end{tabular}

Clinical response: objective clinical response (partial and complete remission are included). Conservative surgery: patients undergoing conservative surgery. ${ }^{a}$ Only 43 patients underwent surgical treatment.

observed in 1 of 43 patients who underwent surgery, and represents $2.3 \%$ pathologic remission.

With respect to factors predictive of response to neoadjuvant or primary hormonal treatment, ER expression was the most powerful predictor in almost all studies published to date. Most of these studies (Ellis et al, 2001; Miller et al, 2003) suggest that an Allred's index $>5$ is associated with a better response to primary hormone therapy. Consensus is not so clear with respect to progesterone receptors, even though in some studies, they have been observed to be a statistically significant predictive factor (Smith, 1991; Kenny et al, 1998; Ellis et al, 2001). In our study, ER expression $\geqslant 90 \%$ in tumour cells was observed to have a significantly higher radiological response rate $(73 \%$ vs $32 \% ; P=0.0026)$, whereas age, tumour size, Karnofsky index and axillary ganglion status showed no statistically significant relationship with response rate.

The expression of HER2 oncogene has traditionally been associated with resistance to treatment with tamoxifen. However, a greater probability of response to aromatase inhibitors has been observed, and a decrease in their expression has been related to a greater therapeutic effect of these inhibitors (Ellis et al, 2001; Eiermann et al, 2001; Ellis, 2004). However, no significant relationship was observed with HER2 overexpression and the progression of the disease. In our series, the small number of patients with HER2 overexpression precluded the detection of significant correlations.

In some trials, changes have been noted in apoptosis markers, such as that identified by the TUNNEL technique or Bcl-2 expression. Although these changes were not associated with a greater probability of pathologic response (Keen et al, 1997; Miller et al, 2003), the decline in proliferative activity caused by aromatase inhibitors is likely to reduce the process of apoptosis (Buzdar and Howell, 2001; Zhu et al, 2004).

In our study, tolerance to exemestane was good and no patient withdrew because of the treatment's side effects. The only grade IIIIV toxicities occurred in 1 case of musculoskeletal pain and two cases of cerebrovascular accident (CVA). The other toxicities were slight and easily resolved and were similar to other studies (Chang et al, 2000; Ellis et al, 2001; Eiermann et al, 2001; Gil et al, 2002; Paridaens et al, 2003; Semiglazov et al, 2005; Smith et al, 2005).

Following surgery, the patients continued receiving systemic treatment with exemestane, except in the cases of disease progres-

\section{REFERENCES}

Allan SG, Rodger A, Smyth JF, Leonard RC, Chetty U, Forrest AP (1985) Tamoxifen as primary treatment of breast cancer in elderly or frail patients: a practical management. $\mathrm{Br}$ Med $\mathrm{J}$ 29: $358-367$ sion. Although the continued administration was not agreed by consensus among the investigators, the results of the ATAC study (ATAC, 2008), the BIG 1-98 study (Coates et al, 2007), and especially the IES 031 study (Coombes et al, 2004), and the ARNO study (Kaufmann et al, 2007) endorse such administration. The results from other studies currently being conducted are awaited.

\section{CONCLUSIONS}

The results of our phase II study assessing the administration of exemestane for 6 months as primary hormonal treatment in postmenopausal patients with ER $(+)$ tumours sized $>3 \mathrm{~cm}$ endorse such administration as being an effective and well tolerated, and is a treatment that makes conservative surgery possible in a high percentage of patients. To the best of our knowledge, this is the first study where a longer than usual administration scheme was used without involving a greater risk of progression of the tumour, or a decrease in the conservative treatment option. Our hypotheses need to be validated in randomised studies exploring the optimal duration of exemestane administration. It is also necessary to identify other predictive factors, apart from the hormonal receptors and c-erbB-2 overexpression, so as to select those patients who can best benefit from this therapeutic approach. Other lines of current research seek to increase the effectiveness of aromatase inhibitors as neoadjuvant treatment by combining them with drugs acting on other therapeutic targets.

\section{ACKNOWLEDGEMENTS}

We thank the hospital pathologists who performed tumour sample analysis and other clinicians who were not part of the research team, but who took responsibility for patient management. EUROCLIN was responsible for collating the data in a database. We also thank Pfizer Spain for providing the medications and for monitoring the study. The funding body had no involvement in data collection, interpretation of the data or the decision to publish. Editorial assistance was provided by Dr Peter R Turner of $t$-SciMed (Reus, Spain).

Astner A, Krainick U, Jonat W, Wallwiene D, Rabb G, Wolf LJ, Eiermann W (2004) Exemestane as preoperative treatment for patients with primary breast cancer. Final results of the German neoadjuvant aromasin initiative (GENARI). Ann Oncol 15(suppl 3): 239 (abstract) 
Bartelink H, Rubens RD, van der Schueren E, Sylvester R (1997) Hormonal therapy prolongs survival in irradiated locally advanced breast cancer: a European Organization for Research and Treatment of Cancer Randomised phase III trial. J Clin Oncol 15: 207-215

Bates T, Riley DL, Houghton J, Fallowfield L, Baum M (1991) Breast Cancer in the Elderly Women: a Cancer Research Campaign trial comparing treatment with tamoxifen and optimal surgery with tamoxifen alone. The elderly Breast Cancer Working Party. Br J Surg 78: 591 - 594

Bergman L, van Dongen JA, van Ooijen B, van Leeuwen FE (1995) Should tamoxifen be a primary treatment choice for elderly breast cancer patients with locoregional disease? Breast Cancer Res Treat 34: 77-83

Bonadonna G, Veronesi U, Brambilla C, Ferrari L, Luini A, Greco M, Bartoli C, Coopmans de Yoldi G, Zucali R, Rilke F, Andreola S, Silvestrini R, Di Fronzo G, Valagussa P (1990) Primary chemotherapy to avoid mastectomy in tumors with diameters of $3 \mathrm{~cm}$ or more. J Natl Cancer Inst 82: 1539-1545

Buzdar A, Howell A (2001) Advances in aromatase inhibition: clinical efficacy and tolerability in the treatment of breast cancer. Clin Cancer Res 7: $2620-2635$

Cataliotti L, Buzdar M, Noguchi S, Bines J (2004) Efficacy of Pre-operative Arimidex (anastrozole) compared with Tamoxifen (PROACT) as neoadjuvant therapy in postmenopausal women with hormone receptor-positive breast cancer. Eur J Cancer suppl 2: 46 (abstract)

Chang J, Powles TJ, Allred DC, Ashley SE, Makris A, Gregory RK, Osborne CK, Dowsett M (2000) Prediction of clinical outcome from primary tamoxifen by expression of biologic markers in breast cancer patients. Clin Cancer Res 6: 616-621

Coates AS, Keshaviah A, Thürlimann B, Mouridsen H, Mauriac L, Forbes JF, Paridaens R, Castiglione-Gertsch M, Gelber R, Colleoni M, Láng I, Del Mastro L, Smith I, Chirgwin J, Nogaret JM, Pienkowski T, Wardley A, Jakobsen EH, Price KN, Goldhirsch A (2007) Five years of letrozole compared with tamoxifen as initial adjuvant therapy for postmenopausal women with endocrine-responsive early breast cancer: update of the study BIG 1-98. J Clin Oncol 25: 486-492

Coombes RC, Hall E, Gibson LJ, Paridaens R, Jassem J, Delozier T, Jones SE, Alvarez I, Bertelli G, Ortmann O, Coates AS, Bajetta E, Dodwell D, Coleman R, Fallowfield L, Mickiewicz E, Andersen J, Lonning PE, Cocconi G, Stewart A, Stuart N, Snowdon CT, Carpentieri M, Massimini G, Bliss J, for the Intergroup Exemestane Study (2004) A randomised trial after two or three years of tamoxifen therapy in postmenopausal women with primary breast cancer. $N$ Engl J Med 350: $1081-1089$

Dixon JM, Jackson J, Renshaw L, Miller WR (2003) Neoadjuvant tamoxifen and aromatase inhibitors: comparisons and clinical outcomes. J Steroid Biochem Mol Biol 86: 295-299

Early Breast Cancer Trialist's Collaborative Group (2005) Effects of chemotherapy and hormonal therapy for early breast cancer on recurrence and 15-year survival: an overview of the randomised trials. Lancet 365: $1687-1717$

Eiermann W, Paepke S, Appfelstaedt J, Llombart-Cussac A, Eremin J, Vinholes J, Mauriac L, Ellis M, Lassus M, Chaudri-Ross HA, Dugan M, Borgs M, Semiglazov V (2001) Letrozole Neo-Adjuvant Breast Cancer Study Group. Preoperative treatment of postmenopausal breast cancer patients with letrozole. A randomised double-blind multicenter study. Ann Oncol 12: $1527-1532$

Ellis MJ, Coop A, Singh B, Mauriac L, Llombert-Cussac A, Jänicke F, Miller WR, Evans DB, Dugan M, Brady C, Quebe-Fehling E, Borgs M (2001) Letrozole is more effective neoadjuvant endocrine therapy than tamoxifen for erbB-1 and/or erbB-2-positive, oestrogen receptor-positive breast cancer: evidence from a phase III randomised trial. J Clin Oncol 19: 3808-3816

Ellis M (2004) Neoadjuvant endocrine therapy as a drug development strategy. Clin Cancer Res 10(suppl): 391-395

Fisher B, Bryant J, Wolmark N, Mamounas E, Brown A, Fisher ER, Wickerham DL, Begovic M, DeCillis A, Robidoux A, Margolese RG, Cruz AB, Hoehn JL, Lees AW, Dimitrov NV, Bear HD (1998) Effect of preoperative chemotherapy on the outcome of women with operable breast cancer. J Clin Oncol 16: 2672-2678

Gazet JC, Markopoulos C, Ford HT, Coombes RC, Bland JM, Dixon RC (1988) Prospective randomised trial of tamoxifen versus surgery in elderly patients with breast cancer. Lancet (i): 679-681

Gazet JC, Ford HT, Coombes RC, Bland JM, Sutcliffe R, Quilliam J, Lowndes $S$ (1994) Prospective randomised trial of tamoxifen vs surgery in elderly patients with breast cancer. Eur J Surg Oncol 20: 207-214

Gil M, Perez X, Azpeitia D, Moreno A, Prieto L, Falo C, Guma A (2001) Toremifene as primary therapy for locally advanced and large-operable breast cancer. Phase II study. The Breast 10(suppl 1): S35 (abstract)
Gil Y, Gil MJ, Moreno A, Perez X, Majem M, Azpeitia D, Guma A (2002) Prognostic factors of tumour response and progression free survival in patients with localized breast cancer treated with toremifene as primary therapy. Proc Am Soc Clin Oncol 21(suppl): 2979 (abstract)

Horobin JM, Preece PE, Dewar JA, Wood RA, Cuschieri A (1991) Long-term follow-up of elderly patients with locoregional breast cancer treated with tamoxifen only. Br J Surg 78: 213-217

Kaufmann M, Jonat W, Hilfricht J, Eidtmann H, Gademann G, Zuna I, von Minckwitz G (2007) Improved overall survival in postmenopausal women with early breast cancer after anastrozole initiated after treatment with tamoxifen compared with continued tamoxifen: The ARNO 95 study. J Clin Oncol 25: 2664-2670

Keen JC, Dixon JM, Miller EP, Cameron DA, Chetty U, Hanby A, Bellamy C, Miller WR (1997) The expression of KI-S1 and bcl-2 and the response to primary tamoxifen therapy in elderly patients with breast cancer. Breast Cancer Res Treat 44: 123-133

Kenny FS, Robertson JFR, Ellis IO (1998) Long term follow-up of elderly patients randomised to primary tamoxifen of wedge mastectomy as initial therapy for operable breast carcinoma. The Breast 7: 335-339

Krainick-Strobel UE, Lichtenegger W, Wallwiener D, Tulusan AH, Jänicke F, Bastert G, Kiesel L, Wackwitz B, Paepke S (2008) Neoadjuvant letrozole in postmenopausal estrogen and/or progesterone receptor positive breast cancer: A phase IIb/III trial to investigate optimal duration of preoperative endocrine therapy. BMC Cancer 8: 62

Landis SH, Murray T, Bolden S, Wingo PA (1998) Cancer statistics 1998 CA Cancer Clin 48: 6-29

Mauri D, Pavlidis N, Ioannidis JPA (2005) Neoadjuvant versus adjuvant systemic treatment in breast cancer: a meta-analysis. J Natl Cancer Inst 97: $188-194$

Mauriac L, Durand M, Avril A, Dilhuydy JM (1990) Neoadjuvant chemotherapy for operable breast carcinoma larger than $3 \mathrm{~cm}$ : a unicentre randomised trial with a 124-month follow-up. Institute Bergonie Bourdeaux Groupe Sein (IBBGS). Ann Oncol 10: 47-52

Merchant TE, McCormick B, Yahalom J, Borgen P (1995) The influence of older age on breast cancer treatment decisions and outcome. Int J Radiat Oncol Biol Phys 33: 565-573

Miller WR, Dixon JM (2002) Endocrine and clnical endpoints of exemestane as neoadjuvant therapy. Cancer Control 9(suppl 2): 9-15

Miller WR, Dixon JM, Macfarlane L, Cameron D, Anderson TJ (2003) Pathological features of breast cancer response following neoadjuvant treatment with either letrozole or tamoxifen. Eur J Cancer 39: $462-468$

Moneer M, El-Didi M, Khaled H (1999) Breast conservative surgery: is it appropriate for locally advanced breast cancer following downstaging by neoadjuvant chemotherapy- a pathological assessment? The Breast 8 : $315-319$

Mustacchi G, Milani S, Pluchinotta A, De Matteis A, Rubagotti A, Perrota A (1994) Tamoxifen or surgery plus tamoxifen as primary treatment for elderly patients with operable breast cancer: The G.R.E.T.A. Trial Group for Research of Endocrine Therapy in the Elderly. Anticancer Res 14: $2197-2200$

NIH (1998) Common Toxicity Criteria CTC version 2.0 DCTD, NCI, NIH, DHHS. CTEP website. http://ctep.cancer.gov/protocolDevelopment/ electronic_applications/docs/ctcv20_4-30-992.pdf

Paridaens R, Dirix L, Lohrisch C, Beex L, Nooij M, Cameron D, Biganzoli L, Cufer T, Duchateau L, Hamilton A, Lobelle JP, Piccart M (2003) Mature results of a randomised phase II multicenter study of exemestane versus tamoxifen as first-line therapy for postmenopausal women with metastatic breast cancer. Ann Oncol 14: 1391-1398

Robertson JF, Ellis IO, Elston CW, Blamey RW (1992) Mastectomy or tamoxifen as initial therapy for operable breast cancer in elderly patients. 5 year follow-up. Eur J Cancer 28A: 908-910

Sandison AJ, Gold DM, Wright P, Jones PA (1996) Breast conservation or mastectomy: treatment choice of women aged 70 years or older. Br J Surg 83: $994-1002$

Semiglazov V, Kletsel A, Zhiltzova V, Ivanov V, Dashyan G, Bozhok A, Melnikova O, Paltuev R, Berstein L (2005) Exemestane (E) vs tamoxifen (T) as neoadjuvant endocrine therapy for postmenopausal women with ER+ breast cancer (T2N1-2, T3N0-1, T4N0M0). Proc Am Soc Clin Oncol 23: 530 (abstract)

Semiglazov VF, Semiglazov VV, Dashyan GA, Ziltsova EK, Ivanov VG, Bozhok AA, Melnikova OA, Paltuev RM, Kletzel A, Berstein LM (2007) Phase II randomised trial of primary endocrine therapy versus chemotherapy in postmenopausal patients with oestrogen receptorpositive breast cancer. Cancer 100: 244-254 
${ }_{\text {OPEN }}^{B J} \mathrm{O}$

Smith IE (1991) Primary (neoadjuvant) medical therapy: Introduction. In: Medical Management of Breast Cancer Powles TJ, Smith IE (eds) pp 259-265. Martin Dunitz: London

Smith IE, Dowsett M, Ebbs SR, Dixon JM, Skene A, Blohmer JU, Ashley SE, Francis S, Walsh G, IMPACT Trialists Group (2005) Neoadjuvant treatment of postmenopausal breast cancer with anastrozole, tamoxifen, or both in combination: the immediate preoperative anastrozole, tamoxifen, or combined with tamoxifen (IMPACT) multicenter doubleblind randomised trial. J Clin Oncol 23: 5108-5116

The Arimidex, Tamoxifen, alone or in combination (ATAC) Trialists' Group (2008) Effect of anastrozole and tamoxifen as adjuvant treatment for early-stage breast cancer: 100-month analysis of the ATAC trial. Lancet Oncol 9: 45-53

Therasse P, Arbuck SG, Eisenhauer EA, Wanders J, Kaplan RS, Rubinstein L, Verweij J, Van Glabbeke M, van Oosterom AT, Christian MC, Gwyther SG (2000) New guidelines to evaluate response to treatment in solid tumors. J Natl Cancer Inst 92: 205-216

Veronesi U, Bonadonna G, Zurrida S, Galimberti V, Greco M, Brambilla C, Luini A, Andreola S, Rilke F, Raselli R, Merson M, Sacchini V, Agresti R (1995) Conservation surgery after primary chemotherapy in large carcinomas of the breast. Ann Surg 222: 612-618
Receptor-positive breast tumour treated with exemestane

A Barnadas et al

Walker LG, Heys SD, Walker MB, Ogston K, Miller ID, Hutcheon AW, Sarkar TK, Ah-See AK, Eremin O (1999) Psychological factors can predict the response to primary chemotherapy in patients with locally advanced breast cancer. Eur J Cancer 35: 1783-1788

Wong ZW, Ellis MJ (2004) First-line endocrine treatment of breast cancer: aromatase inhibitor or antiestrogen? Br J Cancer 90:20-25

Yancik R, Ries LG, Yates JW (1989) Breast cancer in aging women. A population-based study of contrast in stage, surgery and survival. Cancer 63: $976-982$

Zhu L, Chow LWC, Loo WTY, Guan X-Y, Toi M (2004) Her2/neu expression predicts the response to antiaromatase neoadjuvant therapy in primary breast cancer: subgroup analysis from celecoxib antiaromatase neoadjuvant trial. Clin Cancer Res 10: 4639-4644

(c) $\rightleftharpoons$ This work is licensed under the Creative Commons CC) BY No Attribution-NonCommercial-NoDerivs 3.0 License. To view a copy of this license, visit http://creativecommons.org/ licenses/by-nc-nd/3.0/. 